\section{Socioeconomic status and body mass index life course models: the 1993 Pelotas (Brazil) birth cohort}

\section{Condição socioeconômica e índice de massa corporal em modelos de curso de vida: coorte de nascimentos de 1993 de Pelotas, Rio Grande do Sul, Brasil}

\author{
Estatus socioeconómico e índice de masa \\ corporal en modelos de ciclo vital: cohorte \\ de nacimientos de 1993 en Pelotas, \\ Rio Grande do Sul, Brasil
}

Luna Strieder Vieira 1

Juliana dos Santos Vaz 2

Fernando César Wehrmeister 1

Felipe Garcia Ribeiro 1

Janaina Vieira dos Santos Motta 3,4

Helen Denise Gonçalves da Silva 5

Maria Cecília Formoso Assunção 6

\begin{abstract}
This article aims to assess the relationship between an individual's socioeconomic status over their life-course and their body mass index (BMI) at 22 years of age, according to the hypotheses generated by risk accumulation, critical period, and social mobility models. This was a population-based prospective study based on the Pelotas (Brazil) 1993 birth cohort. The risk accumulation, critical period, and social mobility models were tested in relation to a saturated model and compared with a partial F-test. After the best model was chosen, linear regression was carried out to determine the crude and adjusted regression coefficients of the association between socioeconomic status over the life-course and BMI at 22 years of age. The sample was comprised of 3,292 individuals (53.3\% women). We found dose-response effect for both men and women, although the results were opposite. Among men, a lower score in socioeconomic status accumulation model led to a lower BMI average at 22 years of age; whereas among women, a lower score in socioeconomic status accumulation model caused an increase in BMI at 22 years of age.
\end{abstract}

Body Mass Index; Longitudinal Studies; Socioeconomic Factors

\author{
Correspondence \\ L. S. Vieira \\ Universidade Federal de Pelotas. \\ Rua Marechal Deodoro 1160, Pelotas, RS 96020-220, Brasil. \\ luna.stri@gmail.com \\ 1 Universidade Federal de Pelotas, Pelotas, Brasil. \\ 2 Faculdade de Nutrição, Universidade Federal de Pelotas, \\ Pelotas, Brasil. \\ 3 Programa de Pós-graduação em Saúde e Comportamento, \\ Universidade Católica de Pelotas, Pelotas, Brasil. \\ 4 Programa de Pós-graduação em Epidemiologia, Universidade \\ Federal de Pelotas, Pelotas, Brasil. \\ 5 Faculdade de Medicina, Universidade Federal de Pelotas, \\ Pelotas, Brasil. \\ 6 Faculdade de Nutrição, Universidade Federal de Pelotas, \\ Pelotas, Brasil.
}




\section{Background}

Obesity is one of the most significant risk factors for mortality and morbidity, with increasing prevalence and in global proportions 1,2. Between 1975 and 2016, the prevalence of obesity almost tripled worldwide 1. According to the World Health Organization (WHO) estimates, in 2016 over 1.9 billion adults (39\% of adults aged 18 or older) were overweight, and over 650 million of these were obese (13\%) 1 .

Brazil faces a similar scenario; overweight and obesity prevalence has been increasing in all age groups, in both sexes, and at all income levels. The highest growth rate is found among those with lowest family income 3 . In 2019, $55 \%$ of adults were overweight and $20 \%$ were obese 4 .

In addition to nutritional changes, it is important to note that other aspects have changed in Brazil in recent decades. With a predominantly rural population (64\%) in the 1950s; by 2010, Brazil had become an urban country, with more than $84 \%$ of the population living in cities 5 . Over the same period, the population increased from 51.9 million to 190.7 million. Life expectancy increased, from 43.3 to 73.5 years, and the fertility rate decreased dramatically, from 6.2 to 1.9 children, per woman 5 .

Moreover, Brazil is a country with considerable economic inequalities. Its peak was reached in the early 1990s, when the Gini index reached 0.61. From 2000 onwards, the index decreased, reaching 0.52 in 2015 (the lowest rate in 40 years) 6.

Despite the decrease in inequality, shown by the Gini index in 2015, Brazil was, nevertheless, considered to be the world's 10 th most unequal country 6 . In the same year, there was a severe economic crisis in Brazil, generating economic recession and, consequently, a fall in gross domestic product for two consecutive years 7,8. The economy shrank 3.8\% in 2015 and 3.6\% in 2016 7. Moreover, in 2015 , inflation was $10.7 \%$ - almost double that of the previous year $(6.4 \%) 9$ - which, along with the economic recession, also generated a high unemployment rate 10. In 2017, approximately 13 million Brazilians were unemployed 11. Although the difference between those who earned more and those who earned less decreased in 2015, on average, the monthly income decreased among all income brackets 10 . As such, the reduction in inequality occurred mainly because the higher income bracket suffered a more intense reduction than the lower, and not due to an increase in the income of those in the lower income brackets 10 .

With few exceptions, occurrence of a variety of diseases and health problems is more prevalent among the socially vulnerable groups - that is, among those who are poorest, from ethnic minority groups or groups that suffer some kind of discrimination. It is not by chance that health conditions are worse in poorer countries than in richer countries 12.

Studies published in recent years have reported a relationship between socioeconomic status and body mass index (BMI). The studies have shown that, among women, higher socioeconomic status is associated with lower BMI. This association is not observed among men 13. These results have been found in both cross-sectional and longitudinal studies 13 .

The investigation of the cumulative and the dynamic nature of socioeconomic status, over the life course, may better clarify this relationship ${ }^{14}$. In this context, hypotheses arising from conceptual approaches have been proposed to identify mobility of a particular form of exposure throughout one's life, namely the risk accumulation, critical period, and social mobility hypotheses 15 . Thus far, according to a literature review, only two articles have assessed the relationship between socioeconomic status and adult BMI over the life-course using the three models simultaneously. Both studies, however, were conducted in high-income countries. Most articles evaluate only one model, specifically, the social mobility model 16,17,18.

An approach that statistically compares the models that represent each of those hypotheses with the model that considers all possible hypotheses together is interesting for analyzing exposure along a lifetime regarding a particular outcome, since it provides a clearer understanding of each hypothesis 19 . Our study aims to elucidate whether it is the accumulation of low socioeconomic status over the life-course, a specific stage in life, or whether it is a change in socioeconomic status that explains the BMI of young adults. Comparisons of these models by type of socioeconomic status hypothesis can contribute to insights as to the mechanisms underlying young adult's BMI. This information can help identify the highest priority aspects for intervention. 
Therefore, this study aims to identify the life course model that best describes association between socioeconomic status over the life-course and BMI in early adulthood, according to the hypotheses formulated based on the three models mentioned, as well as to explore the relationship between the chosen model and BMI in early adulthood. To that end, we used data from a 1993 birth cohort study in the city of Pelotas, Rio Grande do Sul State, Brazil.

\section{Methods}

The data were collected from the 1993 birth cohort, in the municipality of Pelotas. The cohort is a prospective and population-based study. All of the maternity wards of the municipality were visited daily by a member of the research team from January 1st to December 31st, 1993, and 5,265 births were recorded. A total of 5,249 mothers agreed to participate in the study, while seven mothers were not found, and nine did not agree to participate. The rate of perinatal losses and refusals was $0.3 \% 20$.

This study used data from the 1993 perinatal study and data from the follow-ups, at 11 and 22 years of age. The intention was to interview all cohort members at follow-up. In 2004-2005 (at 11 years of age), those who completed the interviews $(\mathrm{n}=4,452)$, along with those who were known to have died $(\mathrm{n}=141)$, accounted for $87.5 \%$ of the original cohort. All interviews at this follow-up were carried out at the participants' households. In 2015-2016 (at 22 years of age), interviews were held at a clinic, attended by the birth cohort members in Pelotas. Those who completed the interviews $(\mathrm{n}=3,810)$, along with those who were known to have died $(\mathrm{n}=193)$, accounted for $76.3 \%$ of the original cohort (Figure 1).

Further information about the 1993 cohort can be found in the specific methodological publications $20,21,22$.

The BMI outcome was calculated by dividing weight (in kilograms) by height (in meters squared), and was assessed continuously 23 . Weight was measured with a scale attached to a BOD POD plethysmograph (COSMED; https://www.cosmed.com/en/), with 10g precision. Height was measured with a free-standing stadiometer (aluminum and wood) (Harpenden Portable Stadiometer; https://holtain. co.uk/), with $0.1 \mathrm{~cm}$ precision. Anthropometrists were trained according to methodology proposed by Lohman 24 and aligned with the technique proposed by Habicht 25 .

Socioeconomic status was analyzed at three points (birth, 11, and 22 years of age) and was represented by family income. Family income was collected at birth, as a quantitative numerical minimum wage variable, and at 11 and 22 years of age as a continuous variable, expressed in Brazilian currency (BRL). Distribution of these variables at birth and at each of the two follow-ups was divided into tertiles. The first tertile was classified as poor, and the second and third tertiles were classified as not poor. Information collected at all three points in time was combined ( $t 1, t 2$ and $t 3)$ in order to analyze socioeconomic status over the life-course. The variables was thus comprised of eight categories: low status at all three points (birth, 11 and 22 years of age); low-high-low; low-low-high; low-high-high; high-low-low; high-high-low; high-low-high; and high status at all three points.

In order to select the most appropriate life course model, we used a structured modeling approach developed by Mishra et al. ${ }^{19}$. The basic premise of this approach is that, considering the three binary socioeconomic status variables (high/low; socioeconomic status at birth, 11 years of age, and 12 years of age), a saturated model would enable all possible trajectories to have a different mean outcome. Following this methodology, the risk accumulation, critical period, and social mobility models were tested in relation to a saturated model; in which $\mathrm{p}$-values greater than, or equal to, 0.05 represented a better fit of the specific model compared to the saturated model.

To this end, socioeconomic status was transformed into a dummy variable $(S)$ in which the value "0' represented an individual belonging to the "not-poor" category, that is, an individual belonging to the second or third income tertile. In turn, the value "1" represented the individual of the "poor" category, that is, an individual belonging to the first income tertile, thus forming the vector $\delta=\left(\delta_{1}, \ldots, \delta_{j}\right)$, in which $j=1,2$ and 3 . 


\section{Figure 1}

Flowchart of participants in cohort study. The 1993 Pelotas (Brazil) birth cohort.

1993 Pelotas birth cohort

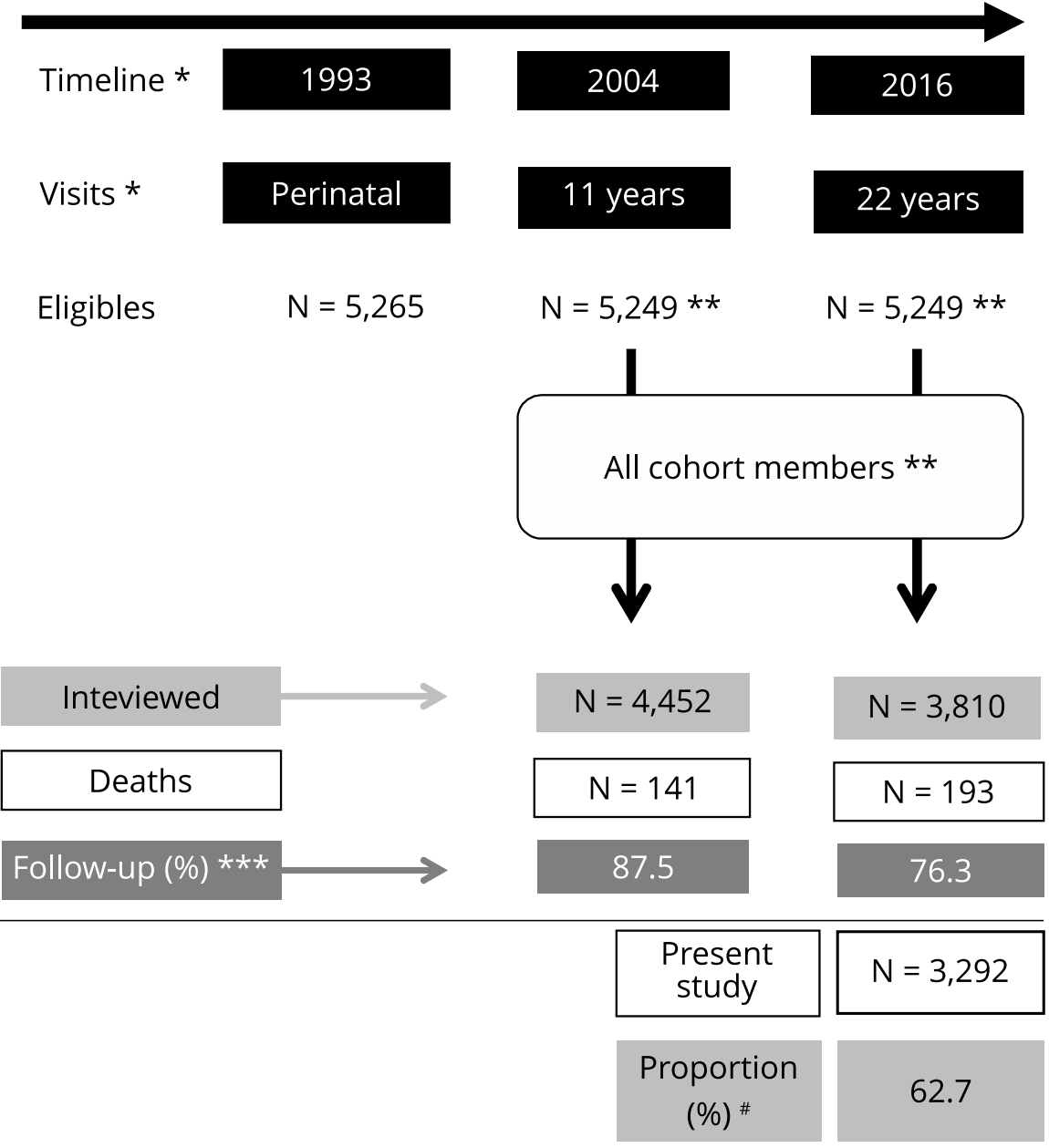

* Black boxes indicate follow-ups that all cohort members were eligible to participate;

** Eligibility refers 5,249 out of 5,265 members whose mothers provided consent to participate in the recruitment phase (Perinatal). Mothers of the remaining 16 refused to participated;

*** Proportion of complete follow-up considering members who participate, added to those known to have die;

\# Present study proportion of participants, considering 3,292 cohort members in relation to the total eligible $(N=5,249)$.

In the saturated model, the expected value for the outcome $(Y)$ was expressed by a linear combination of all $\delta_{j}$ by means of the following equation:

$$
E(Y)=\alpha+\beta_{1} \delta_{1}+\beta_{2} \delta_{2}+\beta_{3} \delta_{3}+\theta_{12} \delta_{1} \delta_{2}+\theta_{13} \delta_{1} \delta_{3}+\theta_{23} \delta_{2} \delta_{3}+\theta_{123} \delta_{1} \delta_{2} \delta_{3}
$$

This model considers that the outcome is related to the individual's socioeconomic status at all data collection times and, in addition, considers the interactions between these times, always comparing them to the expected value for $Y$, for the "consistently poor" category. 
In this article, two examples of the risk accumulation hypothesis were considered: (1) the restricted version, which assumes that the effects of $\delta_{1}, \delta_{2}$ and $\delta_{3}$ are identical in relation to the outcome $\left(\beta_{1}=\beta_{2}=\beta_{3} ; \theta_{12}=\theta_{23}=\theta_{13}=\theta_{123}=0\right)$, that is, regardless of the period, the longer a person has a low socioeconomic status, the greater the risk of a high BMI; and (2) the relaxed version, which assumes that the effects of $\delta_{1}, \delta_{2}$ and $\delta_{3}$ contribute to the outcome but do not, necessarily, contribute in the same way $\left(\beta_{1} \neq \beta_{2} \neq \beta_{3} ; \theta_{12}=\theta_{23}=\theta_{13}=\theta_{123}=0\right)$. The following equations represent, respectively, the restricted and relaxed versions of the risk accumulation model:

$$
E(Y)=\alpha+\beta+\beta \sum_{j} \delta_{j}
$$

and

$$
E(Y)=\alpha+\beta_{1} \delta_{1}+\beta_{2} \delta_{2}+\beta_{3} \delta_{3}
$$

Regarding the critical period, the following model was used to test whether the perinatal period was a critical period: $E(Y)=\alpha+\beta_{1} \delta_{1}$, where $\beta_{2}=\beta_{3} ; \theta_{12}=\theta_{23}=\theta_{13}=\theta_{123}=0$. The following model was used to test whether the critical period was at 11 years of age: $E(Y)=\alpha+\beta_{2} \delta_{2}$, where $\beta_{1}=\beta_{3} ; \theta_{12}=$ $\theta_{23}=\theta_{13}=\theta_{123}=0$. At 22 years of age, the following model was used: $E(Y)=\alpha+\beta_{3} \delta_{3}$, where $\beta_{1}=\beta_{2}$; $\theta_{12}=\theta_{23}=\theta_{13}=\theta_{123}=0$.

Two options were assessed regarding social mobility: intragenerational mobility and any degree of mobility. Two childhood moments $\left(t_{1}\right.$ and $\left.t_{2}\right)$ were used in regard to intragenerational mobility, represented by the equation $E(Y)=\alpha+\beta_{1} \delta_{1}+\beta_{2} \delta_{2}+\theta_{12} \delta_{1} \delta_{2}$. In this case, the test of the hypothesis is $H_{0}: \theta_{12}=-\left(\beta_{1}+\beta_{2}\right) ; \beta_{3}=\theta_{13}=\theta_{23}=\theta_{123}$. Regarding any degree of mobility, all changes, both upwards and downwards, are equally harmful or beneficial. The model for any degree of social mobility can be rewritten as $E(Y)=\alpha+\beta_{1} \delta_{1}+\beta_{2} \delta_{2}+\beta_{3} \delta_{3}+\theta_{12} \delta_{1} \delta_{2}+\theta_{13} \delta_{1} \delta_{3}+\theta_{23} \delta_{2} \delta_{3}$. The test of the hypothesis is $\beta_{2}=\left(\beta_{1}+\beta_{3}\right) \& \theta_{12}=\theta_{23}=-\beta_{2}$.

F tests were carried out to compare each life course model with a saturated model. Higher F values indicate that the mean squares of the model are larger than the residual sum of squares; that is, the higher the F value, the more significant the $\mathrm{p}$-value for the analysis of variance (ANOVA). If more than one life course model has a p-value higher than 0.05 , the model with the highest p-value is chosen.

After selecting the most appropriate model, linear regression was carried out to determine the crude, and adjusted regression coefficients of the relationship between socioeconomic status and BMI at 22 years of age. The following variables were included in the adjusted model: self-reported skin color (variable categorized as white, black or other) and pre-gestational maternal BMI (continuous variable in $\mathrm{kg} / \mathrm{m}^{2}$ ). Due to the interaction of the sex variable with socioeconomic status over the lifecourse and with BMI ( $<0.0001)$, all the analyses were stratified by sex. The statistical analyses were performed using Stata software, version 13.0 (https://www.stata.com).

All of 1993 Pelotas birth cohort follow-ups were approved by the Research Ethics Committee of the School of Medicine, Federal University of Pelotas, and the most recent ethics approval protocol is n. 1.250.366. At all stages, participants and/or their legal guardians signed free and informed consent forms.

\section{Results}

At 22 years of age, 3,810 individuals were assessed, of whom 3,292 (53.3\% women) had complete data for outcome, exposure, and confounding variables and were, therefore, included in the analyses. Men and women had similar average values for BMI, i.e. $25.1 \mathrm{~kg} / \mathrm{m}^{2}$ and $25.5 \mathrm{~kg} / \mathrm{m}^{2}$, respectively (Table 1).

Table 2 shows the saturated and restricted tests according to the risk accumulation (restricted and relaxed), critical period, and mobility hypotheses, stratified by sex. For both men and women, the model with the best fit was the restricted risk accumulation model, with p-values of 0.92 and 0.31 , respectively (Table 2). As the restricted risk accumulation model was the model with the best fit, crude and adjusted linear regression analysis was performed only for this model. In order to represent the restricted risk accumulation model, the low ("poor") socioeconomic status indicator at the different 
Table 1

Characteristics of participants with complete data, stratified by gender. The 1993 Pelotas (Brazil) birth cohort $(\mathrm{N}=3,292)$.

\begin{tabular}{|c|c|c|c|c|c|c|}
\hline & & & \multicolumn{2}{|c|}{ Males $(n=1,539)$} & \multicolumn{2}{|c|}{ Females $(n=1,753)$} \\
\hline & & & n (\%) & $\begin{array}{c}\text { BMI at } 22 \text { years }\left(\mathrm{kg} / \mathrm{m}^{2}\right) \\
\text { [mean }(\mathrm{SD})]\end{array}$ & n (\%) & $\begin{array}{c}\text { BMI at } 22 \text { years }\left(\mathrm{kg} / \mathrm{m}^{2}\right) \\
\text { [mean }(\mathrm{SD})]\end{array}$ \\
\hline \multicolumn{7}{|c|}{ Socioeconomic status trajectories * } \\
\hline 1 & 1 & 1 & $157(10.2)$ & $23.9(0.4)$ & $192(11.0)$ & $26.3(0.5)$ \\
\hline 1 & 0 & 1 & $118(7.7)$ & $24.4(0.5)$ & $177(10.1)$ & $25.9(0.5)$ \\
\hline 1 & 1 & 0 & $155(10.1)$ & $24.4(0.4)$ & $134(7.6)$ & $26.0(0.5)$ \\
\hline 1 & 0 & 0 & $239(15.5)$ & $25.3(0.3)$ & $226(12.9)$ & $25.9(0.4)$ \\
\hline 0 & 1 & 1 & $68(4.4)$ & $25.1(0.6)$ & $105(6.0)$ & $25.2(0.5)$ \\
\hline 0 & 0 & 1 & $186(12.1)$ & $25.1(0.4)$ & $220(12.6)$ & $25.4(0.4)$ \\
\hline 0 & 1 & 0 & $114(7.4)$ & $25.2(0.5)$ & $141(8.0)$ & $26.3(0.5)$ \\
\hline 0 & 0 & 0 & $502(32.6)$ & $25.6(0.2)$ & $558(31.8)$ & $24.6(0.2)$ \\
\hline \multicolumn{7}{|c|}{ Skin color } \\
\hline White & & & $990(64.3)$ & $25.1(0.2)$ & $1104(63.0)$ & $25.2(0.2)$ \\
\hline Black & & & $230(15.0)$ & $25.4(0.4)$ & $269(15.3)$ & $26.2(0.3)$ \\
\hline Mixed & & & 319 (20.7) & $24.8(0.3)$ & 380 (21.7) & $25.7(0.3)$ \\
\hline $\mathrm{BMI}$ at 2 & 2) $[n$ & & $25.1(4.8)$ & - & $25.5(5.8)$ & - \\
\hline Materna & cy & an (SD)] & $22.8(3.7)$ & - & $22.9(3.7)$ & - \\
\hline
\end{tabular}

BMI: body mass index; SD: standard deviation.

* $1=$ low; 0 = high.

Table 2

Saturated and restricted tests according to the assumptions of risk accumulation, critical period, and social mobility according to the hypotheses of risk accumulation, critical period, and social mobility by sex. The 1993 Pelotas (Brazil) birth cohort $(\mathrm{N}=3,292)$.

\begin{tabular}{lcccc}
\hline Hypothesis & \multicolumn{2}{c}{ Men $(\mathbf{n}=\mathbf{1 , 5 3 9 )}$} & \multicolumn{2}{c}{ Women $(\mathbf{n}=\mathbf{1 , 7 5 3 )}$} \\
& F statistic & p-value & F statistic & p-value \\
\hline $\begin{array}{l}\text { No effect } \\
\text { Risk accumulation }\end{array}$ & 3.17 & 0.002 & 3.11 & 0.003 \\
$\quad$ Strict & 0.33 & & & \\
$\quad$ Relaxed & 0.48 & 0.922 & 1.19 & 0.310 \\
Critical period & & 0.749 & 1.33 & 0.256 \\
Perinatal & 1.91 & & & 0.109 \\
11 years & 2.12 & 0.077 & 1.74 & 0.032 \\
22 years & 2.46 & 0.048 & 2.30 & 0.004 \\
Mobility & & 0.022 & 3.19 & 0.050 \\
Intragenerational & 1.82 & & & 0.033 \\
Any mobility & 0.28 & 0.105 & 2.22 & 2.44 \\
\hline
\end{tabular}

time points studied was added to obtain a score over the course of life, where scores could vary from 0 to 3 points.

Table 3 shows the results of the crude and adjusted analyses between the restricted risk accumulation model (best fit) and BMI. For both sexes, accumulation of low socioeconomic status, from birth to 22 years of age, was associated with the BMI at 22 years of age in both crude and adjusted analyses. However, association had opposite effect regarding sex: Among men, BMI at 22 years of age decreased 
Table 3

Crude and adjusted linear regression coefficients for the association between socioeconomic status accumulation and body mass index (BMI) by sex. The 1993 Pelotas (Brazil) birth cohort $(\mathrm{N}=3,292)$.

\begin{tabular}{|c|c|c|c|c|}
\hline \multirow[t]{2}{*}{ Characteristic } & \multicolumn{2}{|c|}{ Men } & \multicolumn{2}{|c|}{ Women } \\
\hline & $\begin{array}{l}\beta \text { crude } \\
(95 \% \mathrm{Cl})\end{array}$ & $\begin{array}{c}\beta \text { adjusted * } \\
(95 \% \mathrm{Cl})\end{array}$ & $\begin{array}{l}\beta \text { crude } \\
(95 \% \mathrm{Cl})\end{array}$ & $\begin{array}{c}\beta \text { adjusted * } \\
(95 \% \mathrm{Cl})\end{array}$ \\
\hline \multicolumn{5}{|c|}{ Socioeconomic status accumulation score ** } \\
\hline 0 & - & - & - & - \\
\hline 1 & $-0.37(-0,96 ;-0.21)$ & $-0.31(-0.87 ; 0.25)$ & $1.12(0.46 ; 1.79)$ & $1.03(0.39 ; 1.68)$ \\
\hline 2 & $-1.10(-1.76 ;-0.44)$ & $-0.98(-1.62 ;-0.34)$ & $1.14(0.41 ; 1.87)$ & $1.06(0.35 ; 1.78)$ \\
\hline 3 & $-1.69(-2.54 ;-0.83)$ & $-1,39(-2,22 ;-0.56)$ & $1.65(0.71 ; 2.59)$ & $1.57(0.64 ; 2.50)$ \\
\hline
\end{tabular}

by $0.30 \mathrm{~kg} / \mathrm{m}^{2}$ on average, when changing the low socioeconomic status accumulation score from 0 to 1 ; by $0.92 \mathrm{~kg} / \mathrm{m}^{2}$, when changing the score from 0 to 2 ; and by $1.33 \mathrm{~kg} / \mathrm{m}^{2}$, when changing the score from 0 to 3; Among women, BMI at 22 years of age increased $1.05 \mathrm{~kg} / \mathrm{m}^{2}$ on average, when changing the low socioeconomic status accumulation score from 0 to $1 ;$ by $1.10 \mathrm{~kg} / \mathrm{m}^{2}$, when changing the score from 0 to 2 ; and by $1.64 \mathrm{~kg} / \mathrm{m}^{2}$ when changing the score from 0 to 3 .

\section{Discussion}

By using a structured modeling approach to select the most appropriate model for studying the relationship between socioeconomic status over the life-course and BMI at 22 years of age, we found that the restricted version of the risk accumulation model was the most adequate for both sexes.

According to the study results, the relationship between socioeconomic status and BMI was one of accumulation. As such, there appears to be no specific phase or critical period, but rather a doseresponse relationship - meaning that the greater the number of points in time when socioeconomic status was low, the lower the BMI of men and the higher the BMI of women. We identified the risk accumulation model as the most adequate model for studying the association between socioeconomic status over the life-course and BMI, at 22 years of age. This can be explained by the fact that health is, fundamentally, shaped by time 26 ; most chronic illnesses in adults will probably not be explained by critical periods in the uterus or childhood, but rather as consequences of long-term accumulation and complex interactions between early and late exposures 27 . Previous reports show that the additive effects of low socioeconomic status, at the different stages of life, influence BMI in adulthood $16,17,28$. However, risk accumulation may also be due to grouping of types of exposure - for instance, individuals from poorer socioeconomic contexts are also more likely to have been born with low weight 29; to have had unhealthy diets in childhood, adolescence, and adulthood 30; and to have done less physical activity in leisure time, in both adolescence and adulthood 31.

Among women, the highest average BMI is found among those with the lowest socioeconomic status, perhaps because they have had less schooling and, consequently, are less concerned with the significance of diet quality and physical activity practice 32 . This can be demonstrated in studies in which the prevalence of obesity was lower among women with more years of schooling and higher family income 33,34,35. Parity can also influence BMI. There is evidence that women's education is inversely related to birth rate 36,37 . As childbirth is associated with long-term increase in obesity 38,39 , this could be one of the reasons why BMI is higher in women with lower socioeconomic status. This result reinforces the need for strategies that encourage the adoption of a healthy lifestyle before first pregnancy and throughout the reproductive cycle. Furthermore, it indicates that public health 
interventions are necessary in the community to encourage physical activity and adoption of healthy eating behaviors 40 .

Only two studies were identified assessing the relationship between socioeconomic status over the life-course and BMI in early adulthood with a methodology similar to ours 16,17. Both studies found that, for women, the model with the best fit was the risk accumulation model. A study conducted in the United Kingdom with 5,362 individuals, followed from birth to 53 years of age, showed that an increase of one point on the low socioeconomic status accumulation score increased the BMI by $0.91 \mathrm{~kg} / \mathrm{m}^{2}$ on average in women at 53 years of age 16. In Sweden, Padyab \& Norberg 17 also found that, among a sample of 3,340 people followed from birth to 60 years of age, an increase of one point on the low socioeconomic status accumulation score led to an average increase of $0.44 \mathrm{~kg} / \mathrm{m}^{2}$ in BMI among women at 53 years of age.

There is no consensus in the literature about the best model for assessing the relationship between socioeconomic status over the life-course and BMI among men. Murray et al. 16 found the best model to be the critical period in childhood; lower socioeconomic status in childhood was associated with a higher average BMI in adulthood (53 years of age). In turn, Padyab \& Norberg 17 did not find any association between socioeconomic status and BMI at 60 years of age. In our study, the best model for men was the restricted risk accumulation model, whereby an increase in the low socioeconomic status accumulation score led to a lower average BMI at 22 years of age. The difference observed between the study conducted by Murray et al. 16 and our study could be due to the populations they investigated. The cited study assessed a sample of individuals from the United Kingdom, a highincome country, which showed a smaller number of individuals in the downward trajectory and few participants with a critical period of low socioeconomic status at 26 years of age (53 individuals) and at 43 years of age (26 individuals). In our study, which was conducted in a medium-income country, the number of individuals in the different socioeconomic status trajectories was more homogenous. However, this type of analysis is still incipient. Studies are lacking with samples from medium- or low-income countries for further comparisons and a more in-depth discussion.

A hypothesis for explaining different results for men and women is that ideal body weight differs according to a person's sex. Ideal body weight is socially constructed and depends on the moment in time and culture. Nevertheless, prior research has shown that women tend to consider a slimmer body to be ideal; whereas for men body weight becomes a physical marker of dominance, and a larger body is preferred 41,42,43. However, more research is needed to fully understand the sex-specific mechanism linking socioeconomic status and obesity. Moreover, women suffer greater sociocultural pressure not to be overweight when compared to men. This pressure is even greater among women with higher socioeconomic status in the context investigated 44,45.

The strengths of this study include its design: a prospective, population-based birth cohort with socioeconomic status measurements taken at three periods in life; the high follow-up rate; and the quality control carried out at the different stages of the study (birth, adolescence, and adulthood), which included interviewer training, standardization of anthropometric measurements, instrument calibration, and testing and data quality control. These measures ensured that the data analyzed was more reliable. Note that, the analysis methodology, as it enables simultaneous assessment of three life course models and examination of heterogeneity of the life course models according to the outcome and stratified analysis. These possibilities enable us to identify whether there is a stage in life that needs intervention(s) aimed at preventing certain outcomes in adulthood. Additionally, in this study, care was taken in the choice of adjustment variables. The analyses were not adjusted for mediating variables such as smoking, alcohol consumption, physical activity, and diet, this being a common error in articles that evaluate association between socioeconomic status throughout life and BMI in adult life $17,46,47$. The originality of the study is also noteworthy since no previous studies in low, or medium, income countries were found that assessed the relationship between socioeconomic status over the life-course with BMI in adulthood using the statistical method we employed.

As limitations, it is important to mention the use of the income variable for assessing socioeconomic status, as well as its dichotomization, which was originally a continuous variable. Regarding socioeconomic status indicators, most studies chose schooling and occupation48. Family income is not used so frequently, but it might be as important as schooling and occupation, or different from them. Although schooling and occupation capture dimensions of socioeconomic status that are based 
on the individual, family income is linked to both schooling and occupation, and reflects the standard of living that family members experience when sharing goods and services 48 .

The choice of income is justified by the fact that Brazil has shown an overall growth in education over the last 30 years, due to several incentives towards making higher education levels accessible by social classes that used to be excluded 49 . Therefore, it is reasonable to assume that discriminating according to years of schooling for younger individuals would reduce the effect on the data; thus, making family income a more discriminating indicator of some health outcomes. The limitations regarding the use of occupation as variable, in countries such as Brazil, are the lack of precision in its measurement and classification. The process of collecting and classifying occupational data takes time, and the cost is high, since the questionnaires must include several questions in order to properly characterize occupation (job title, description of the type of job, type of company, sector, type of employment relationship), which is not always possible for studies in those countries. Additionally, even if all the necessary questions are included, coding this information is complex ${ }^{49}$. Despite reducing the power of the analysis, socioeconomic status dichotomization was necessary in order to study the relationship of the life course models with BMI at 22 years of age, since the analysis employed requires a dummy variable 19 .

Another limitation of this study was the impossibility of assessing intergenerational mobility, since at age 22, a high percentage of participants reported not being financially independent (41\%), so that the income of most participants at 22 years of age reflected their parents' income. In future analyses, when the participants will be older, it will be possible to continue this study and fill this gap in intergenerational mobility.

The choice of the use of the BMI should also be discussed. Although acknowledged to be a useful measure in population terms for overweight and obesity, it is not a gold standard for measuring body composition, which may cause some limitations. For example, a man and a woman of the same height and weight may have the same BMI but have different body compositions. Although BMI does not provide information related to the amount and distribution of body fat, this measure is associated with mortality. In a population-based cohort study, Bhaskaran et al. 50 assessed, approximately, four million individuals and found a J-shaped association between BMI and overall mortality. Additionally, a BMI of $30 \mathrm{~kg} / \mathrm{m}^{2}$ has excellent specificity and positive predictive value for diagnosis of obesity in both sexes 51 .

\section{Conclusions}

The process of reducing obesity and chronic diseases requires a deep understanding of risk factors from early life. This study has filled a gap in the literature concerning association between socioeconomic status over the life-course and BMI in medium-income countries and clarified the relevance of investigating the most appropriate life course model for a particular form of exposure. By assessing the relationship between socioeconomic status over the life-course and BMI, our study showed that the risk accumulation model was more appropriate than the critical period or social mobility models. Additionally, the study showed different results for men and women, with a dose-response effect. Among men, an increase in the low socioeconomic status accumulation score led to lower average BMI at 22 years of age; whereas among women, an increase in the low socioeconomic status accumulation score caused an increase in BMI at 22 years of age. Our results suggest that efforts should be concentrated on reducing the social inequality that is associated with BMI, considering the difference between men and women. Although the results of a single municipality cannot be extrapolated to the rest of the country, the results can be extrapolated to the population of the same age and in settings with similar sociodemographic characteristics. The results observed in Pelotas are nevertheless a reflection of phenomena that happen in Brazil as a whole, and thus help to promote a better understanding of the epidemiological transition process. 


\section{Contributors}

L. S. Vieira contributed to the study conception and design, data analysis and interpretation, and writing. J. S. Vaz contributed to the study conception and design, data interpretation, and critical review. F. C. Wehrmeister contributed to the data analysis and interpretation and critical review. F. G. Ribeiro and M. C. F. Assunção contributed to the study conception and design, data analysis and interpretation, and critical review. J. V. S. Motta contributed to the study conception and design and critical review. $\mathrm{H}$. D. G. Silva contributed to the critical review. All authors approved the final version of the article.

\section{Additional informations}

ORCID: Luna Strieder Vieira (0000-0001-99468575); Juliana dos Santos Vaz (0000-0002-2880767X); Fernando César Wehrmeister (0000-00017137-1747); Felipe Garcia Ribeiro (0000-00026068-1288); Janaína Vieira dos Santos Motta (00000002-3755-845X); Helen Denise Gonçalves da Silva (0000-0001-6470-3352); Maria Cecília Formoso Assunção (0000-0002-7767-8835).

\section{References}

1. NCD Risk Factor Collaboration. Worldwide trends in body-mass index, underweight, overweight, and obesity from 1975 to 2016: a pooled analysis of 2416 population-based measurement studies in 128.9 million children, adolescents, and adults. Lancet 2017; 390:2627-42.

2. NCD Risk Factor Collaboration. Trends in adult body-mass index in 200 countries from 1975 to 2014: a pooled analysis of 1698 population-based measurement studies with 19.2 million participants. Lancet 2016; 387:1377-96.

3. Instituto Brasileiro de Geografia e Estatística. Pesquisa de Orçamentos Familiares 20082009: antropometria e estado nutricional de crianças, adolescentes e adultos do Brasil. Rio de Janeiro: Instituto Brasileiro de Geografia e Estatística; 2010.

4. Ministério da Saúde. Vigitel Brasil 2019: vigilância de fatores de risco e proteção para doenças crônicas por inquérito telefônico. Brasília: Ministério da Saúde; 2020.

5. Instituto Brasileiro de Geografia e Estatística. Censo Demográfico 2010: características da população e dos domicílios, resultados do universo. Rio de Janeiro: Instituto Brasileiro de Geografia e Estatística; 2012.

6. United Nations. Human Development Report 2016: human development for everyone. http://hdr.undp.org/sites/default/files/2016_ human_development_report.pdf (accessed on 20/Nov/2018).

7. The World Bank Group. World development indicators. https://data.worldbank.org/coun try $/$ brazil locale $=$ pt $\% 20$ world - developmen t-indicators (accessed on 15/Jan/2019).

8. Barbosa Filho FH. A crise econômica de 2014/2017. Estud Av 2017; 31:51-60.

9. Instituto Brasileiro de Geografia e Estatística. Índice de Preços ao Consumidor Amplo IPCA. Séries históricas. https://www.ibge.gov. br/estatisticas/economicas/precos-e-custos/ 9256-indice-nacional-de-precos-ao-consumi dor-amplo.html? $=\& \mathrm{t}=$ series-historicas (accessed on $18 / \mathrm{Feb} / 2019)$.

10. Instituto Brasileiro de Geografia e Estatística. Pesquisa Nacional por Amostra de Domicílios: síntese de indicadores 2015. Rio de Janeiro: Instituto Brasileiro de Geografia e Estatística; 2016.

11. Instituto Brasileiro de Geografia e Estatística. Pesquisa Nacional por Amostra de Domicílios: principais destaques da evolução do mercado de trabalho no Brasil, 2012-2018. https://www.ibge.gov.br/estatisticas/so ciais/trabalho/17270-pnad-continua.html? edicao $=22889 \& \mathrm{t}=$ downloads $($ accessed on $06 /$ $\mathrm{Feb} / 2019)$.

12. Barreto ML. Desigualdades em saúde: uma perspectiva global. Ciênc Saúde Colet 2017; 22:2097-108. 
13. Newton S, Braithwaite D, Akinyemiju TF. Socio-economic status over the life course and obesity: systematic review and meta-analysis. PLoS One 2017; 12:e0177151.

14. Pollitt RA, Rose KM, Kaufman JS. Evaluating the evidence for models of life course socioeconomic factors and cardiovascular outcomes: a systematic review. BMC Public Health 2005; 5:7.

15. Kuh D, Ben-Shlomo Y. A life course approach to chronic disease epidemiology: tracing the origins of ill-health from early to adult life. Oxford: Oxford University Press; 1997.

16. Murray ET, Mishra GD, Kuh D, Guralnik J, Black S, Hardy R. Life course models of socioeconomic position and cardiovascular risk factors: 1946 birth cohort. Ann Epidemiol 2011; 21:589-97.

17. Padyab M, Norberg M. Socioeconomic inequalities and body mass index in Vasterbotten County, Sweden: a longitudinal study of life course influences over two decades. Int J Equity Health 2014; 13:35.

18. Vieira LS, Bierhals IO, Vaz JS, Meller FO, Wehrmeister FC, Assunção MCF. Socioeconomic status throughout life and body mass index: a systematic review and meta-analysis. Cad Saúde Pública 2019; 35:e0125518.

19. Mishra G, Nitsch D, Black S, De Stavola B, Kuh D, Hardy R. A structured approach to modelling the effects of binary exposure variables over the life course. Int J Epidemiol 2009; 38:528-37.

20. Victora CG, Hallal PC, Araujo CL, Menezes AM, Wells JC, Barros FC. Cohort profile: the 1993 Pelotas (Brazil) birth cohort study. Int J Epidemiol 2008; 37:704-9.

21. Gonçalves H, Wehrmeister FC, Assunção MCF, Tovo-Rodrigues L, Oliveira IO, Murray J, et al. Cohort profile update: the 1993 Pelotas (Brazil) Birth Cohort follow-up at 22 years. Int J Epidemiol 2018; 47:1389-90e.

22. Victora CG, Araújo CLP, Menezes AMB, Hallal PC, Vieira MF, Neutzling MB, et al. Methodological aspects of the 1993 Pelotas (Brazil) birth cohort study. Rev Saúde Pública 2006; 40:39-46.

23. World Health Organization. Health-topics. http://www.euro.who.int/en/health-topics/ disease-prevention/nutrition/a-healthy-lifes tyle/body-mass-index-bmi (accessed on 17/ Jan/2019).

24. Lohman TG. Anthropometric standardization reference manual. Champaign: Human Kinetics Books; 1988.

25. Habicht JP. Estandarización de métodos epidemiológicos cuantitativos sobre el terreno. Bol Oficina Sanit Panam 1974; 76:375-84.

26. Smith GD. Life-course approaches to inequalities in adult chronic disease risk. Proc Nutr Soc 2007; 66:216-36.

27. Smith GD. Lifecourse approaches to health inequalities. In: Smith GD, editor. Health inequalities: life course approaches. Bristol: Policy Press; 2003. p. xii-lix.
28. Heraclides A, Brunner E. Social mobility and social accumulation across the life course in relation to adult overweight and obesity: the Whitehall II study. J Epidemiol Community Health 2010; 64:714-9.

29. Martinson ML, Reichman NE. Socioeconomic inequalities in low birth weight in the United States, the United Kingdom, Canada, and Australia. Am J Public Health 2016; 106:748-54.

30. Darmon N, Drewnowski A. Does social class predict diet quality? Am J Clin Nutr 2008; 87:1107-17.

31. Silva I, Mielke G, Bertoldi A, Arrais P, Luiza $\mathrm{V}$, Mengue SS, et al. Overall and leisure-time physical activity among Brazilian adults: national survey based on the Global Physical Activity Questionnaire. J Phys Act Health 2018; 15:212-8.

32. Assumpção D, Domene SMÁ, Fisberg RM, Canesqui AM, Barros MBA. Diferenças entre homens e mulheres na qualidade da dieta: estudo de base populacional em Campinas, São Paulo. Ciênc Saúde Colet 2017; 22:347-58.

33. Gigante DP, Dias-da-Costa JS, Olinto MTA, Menezes AMB, Macedo S. Obesidade da população adulta de Pelotas, Rio Grande do Sul, Brasil e associação com nível sócio-econômico. Cad Saúde Pública 2006; 22:1873-9.

34. Basto-Abreu A, Barrientos-Gutierrez T, Zepeda-Tello R, Camacho V, Gimeno Ruiz de Porras D, Hernández-Ávila M. The relationship of socioeconomic status with body mass index depends on the socioeconomic measure used. Obesity (Silver Spring) 2018; 26:176-84.

35. Ministério da Saúde. Vigitel Brasil 2006: vigilância de fatores de risco e proteção para doenças crônicas por inquérito telefônico. Brasília: Ministério da Saúde; 2007.

36. Kravdal $\varnothing$, Rindfuss RR. Changing relationships between education and fertility: a study of women and men born 1940 to 1964. Am Sociol Rev 2008; 73:854-73.

37. United Nations. World population monitoring, 2003: population, education and development. New York: United Nations; 2005.

38. Li W, Wang Y, Shen L, Song L, Li H, Liu B, et al. Association between parity and obesity patterns in a middle-aged and older Chinese population: a cross-sectional analysis in the Tongji-Dongfeng cohort study. Nutr Metabol 2016; 13:72.

39. Hajiahmadi M, Shafi H, Delavar MA. Impact of parity on obesity: a cross-sectional study in Iranian women. Med Princ Pract 2015; 24:70-4.

40. World Health Organization. Obesity: preventing and managing the global epidemic. Geneva: World Health Organization; 2000. (WHO Technical Report Series, 894).

41. McArthur LH, Holbert D, Peña M. An exploration of the attitudinal and perceptual dimensions of body image among male and female adolescents from six Latin American cities. Adolescence 2005; 40:801-16.

42. McLaren L. Socioeconomic status and obesity. Epidemiol Rev 2007; 29:29-48. 
43. Sobal J. Obesity and socioeconomic status: a framework for examining relationships between physical and social variables. Med Anthropol 1991; 13:231-47.

44. Su D, Esqueda OA, Li L, Pagan JA. Income inequality and obesity prevalence among OECD countries. J Biosoc Sci 2012; 44:417-32.

45. Finkelstein EA, Ruhm CJ, Kosa KM. Economic causes and consequences of obesity. Annu Rev Public Health 2005; 26:239-57.

46. Aitsi-Selmi A, Batty GD, Barbieri MA, Silva AA, Cardoso VC, Goldani MZ, et al. Childhood socioeconomic position, adult socioeconomic position and social mobility in relation to markers of adiposity in early adulthood: evidence of differential effects by gender in the 1978/79 Ribeirao Preto cohort study. Int J Obes (Lond) 2013; 37:439-47.

47. Gustafsson PE, Persson M, Hammarstrom A. Socio-economic disadvantage and body mass over the life course in women and men: results from the Northern Swedish Cohort. Eur J Public Health 2012; 22:322-7.
48. Duncan GJ, Daly MC, McDonough P, Williams DR. Optimal indicators of socioeconomic status for health research. Am J Public Health 2002; 92:1151-7.

49. Alves MTG, Soares JF. Medidas de nível socioeconômico em pesquisas sociais: uma aplicação aos dados de uma pesquisa educacional. Opin Pública 2009; 15:1-30.

50. Bhaskaran K, Dos-Santos-Silva I, Leon DA, Douglas IJ, Smeeth L. Association of BMI with overall and cause-specific mortality: a population-based cohort study of 3.6 million adults in the UK. Lancet Diabetes Endocrinol 2018; 6:944-53.

51. Okorodudu DO, Jumean MF, Montori VM, Romero-Corral A, Somers VK, Erwin PJ, et al. Diagnostic performance of body mass index to identify obesity as defined by body adiposity: a systematic review and meta-analysis. Int J Obes (Lond) 2010; 34:791-9. 


\section{Resumo}

$O$ artigo busca avaliar a relação entre condição socioeconômica ao longo da vida e índice de massa corporal (IMC) aos 22 anos de idade, de acordo com as hipóteses geradas pelos modelos de acúmulo de riscos, período crítico e mobilidade social. Este é um estudo prospectivo de base populacional, na coorte de nascimentos de 1993 de Pelotas, Rio Grande do Sul, Brasil. Os modelos de acúmulo de riscos, período crítico e mobilidade social foram testados em relação a um model saturado, e comparados através de um teste F parcial. Após escolher o melhor modelo, a análise de regressão linear foi realizada para determinar os coeficientes de regressão, brutos e ajustados, da associação entre a condição socioeconômica ao longo da vida e o IMC aos 22 anos. A amostra consistia em 3.292 indivíduos (53,3\% mulheres). Foram identificados efeitos de dose-resposta em homens e mulheres, embora os efeitos fossem opostos. Entre os homens, um aumento na pontuação baixa no modelo de acúmulo de condição socioeconômica levou a um IMC médio mais baixo aos 22 anos de idade; enquanto isso, nas mulheres, um aumento na pontuação baixa no modelo de acúmulo de condição socioeconômica levou a um aumento no IMC aos 22 anos de idade.

Índice de Massa Corporal; Estudos Longitudinais; Fatores Socioeconômicos

\section{Resumen}

El objetivo de este artículo es evaluar la relación entre el estatus socioeconómico a lo largo del ciclo vital y el indice de masa corporal (IMC) con 22 años de edad, según las hipótesis generadas por riesgo de acumulación, período crítico y modelos de movilidad social. Se trata de un estudio prospectivo de base poblacional con la cohorte de nacimiento de 1993 en Pelotas, Rio Grande do Sul, Brasil. Se probaron tanto el riesgo de acumulación, como el período crítico y modelos de movilidad social, en relación con un modelo saturado y comparado mediante un F-test parcial. Tras haber elegido el mejor modelo, se llevó a cabo una regresión lineal para determinar los coeficientes de asociación crudos y ajustados entre estatus socioeconómico, a lo largo del ciclo vital, e IMC a los 22 años de edad. La muestra estuvo compuesta por 3.292 individuos (53,3\% mujeres). Se encontraron efectos dosis-respuesta para ambos hombres y mujeres, a pesar de que los efectos fueron opuestos. Entre hombres, el aumento en la puntación del modelo de acumulación en el estatus socioeconómico bajo condujo a un promedio más bajo de IMC a los 22 años de edad, mientras que, entre mujeres, el aumento en la puntuación del modelo de acumulación en el estatus socioeconómico bajo provocó un incremento en el IMC a los 22 años de edad.

Indice de Masa Corporal; Estudios

Longitudinales; Factores Socioeconómicos
Submitted on $03 / \mathrm{Sep} / 2020$

Final version resubmitted on 17/Dec/2020

Approved on 29/Jan/2021 